\title{
Study on Fiscal Measures to Promote Healthy Development of Shared Bicycle
}

\author{
Xiuling $\mathrm{Wu}$ \\ Dongfang College \\ Shandong University of Finance and Economics \\ Tai'an, China
}

\begin{abstract}
In recent years, shared bicycle has developed rapidly, and has spread all over the cities in China, especially in the first-tier cities. The support and encouragement policies of the governments at all levels to shared bicycle industry are also increasing, and the shared bicycle market continues to grow at a high speed. However, as more and more enterprises seize the market of shared bicycle, there are many problems in shared bicycle market. Shared bicycle effectively saves resources and improves urban traffic congestion. We should encourage it to develop healthfully. This paper mainly studies how to take financial measures to promote the healthy development of shared bicycle.
\end{abstract}

Keywords—shared bicycle; government; financial measures

\section{INTRODUCTION}

In recent years, shared bicycles have spread all over China, especially in the first-tier cities. Shared bicycle is to provide bicycle sharing services on campus, subway stations, bus stops, residential areas, business areas and public service areas. Shared bicycle is essentially a new type of vehicle leasing business - bicycle rental business, which relies mainly on carriers for bicycles. It can make full use of the bicycle's travel slump caused by rapid economic development and maximize the use of public road resources. At the same time, it plays a role in the health of the body. With the gradual popularity of this mode of travel, the shared bicycle brands emerge in endlessly. The government and governments at all levels have increased the support and encouragement policies of the shared bicycle industry, and the shared bicycle market continues to grow rapidly. But as more and more enterprises seize the market of shared bicycle, there are many problems in shared bicycle market. This paper studies how to take measures to promote the healthy development of shared bicycle from the perspective of finance.

\section{REVIEW OF LITERATURE}

\section{A. Research on the Perspective of Public Management}

From the perspective of public administration, Li Mei puts forward the government as the provider of public service, the executor of urban management, the guardian of the mass property and the core values. It is necessary to take effective measures to solve the problem of market failure and to provide a good environment for the development of shared bicycle and promote its healthy and orderly development.

\section{B. Research on the Use of Econometric Tools}

Guo Meng uses econometric tools to study the saturation of shared bicycle. Through research, it is found that the shared bicycle market is not saturated in our country. The shared bicycle market still has great potential for development.

Zhang Rongjin, using the SWOT model, analyzes the internal and external environment of ofo development, and puts forward four development strategies of SO, ST, WO and WT through the combination of internal and external factors.

Research on the legal issues involved in shared bicycle

Xiang Chunyan studies the responsibility of the traffic accidents in the process of sharing the bicycle, and gives the corresponding countermeasures from the legal aspects, such as the disorderly, disorderly, disorderly, damage and so on.

\section{DEVELOPMENT STATUS AND PREDICTION}

\section{A. Scale of the Shared Bicycle Enterprises in China}

At present, there are more than 70 shared bicycle industries in China, and the competition is fierce. The large scale and rapid development were led by the two giants of the motorbike and ofo, and the relatively small shared bicycle enterprises, such as rode bicycle, harrow, bicycle and yam, were also running steadily, as shown in "Table I".

TABLE I. SHARED BICYCLE ENTERPRISE

\begin{tabular}{|l|l|}
\hline $\begin{array}{l}\text { Steadily developing large scale } \\
\text { shared bicycle enterprises }\end{array}$ & Mobike,ofo \\
\hline $\begin{array}{l}\text { Steady development of small and } \\
\text { medium shared bicycle } \\
\text { enterprises }\end{array}$ & $\begin{array}{l}\text { lool cycling, harrow, rides, rye, } \\
\text { Yongan, single, intelligent, CCbike, } \\
\text { panda, single, easy, single, and } \\
\text { small, and so on. }\end{array}$ \\
\hline $\begin{array}{l}\text { Shared bicycle enterprise that } \\
\text { has gone bankrupt }\end{array}$ & $\begin{array}{l}\text { Wukong bicycle, macho bicycle, } \\
\text { little blue bike, Xiaoming bicycle. }\end{array}$ \\
\hline
\end{tabular}

The rapid development of the shared bicycle industry and the broad market prospects have made many large enterprises stepping into the shared bicycle industry, such as Alibaba, Ham group, Sky and capital, ant Gold clothes and 
Jun Li capital. Although the entry of these large enterprises has greatly promoted the development of the shared bicycle industry, it will further intensify the competition of shared bicycle.

\section{B. The Number of Shared Bicycle and the Size of the Users}

As of December 2017, the total number of shared bicycles was about 23 million vehicles. In Hangzhou, for example, by the end of March 30, 2018, there were 770 thousand different brands of shared bicycles in Hangzhou City, and at the end of last year, the number of shared bicycles in Hangzhou was 883 thousand.

In terms of user size, shared bicycle has become the most significant type of Internet application in the second half of 2017. According to statistics, as of December 2017, the share of domestic users of shared bicycles has reached 221 million, accounting for $28.6 \%$ of the total Internet users. The user scale increased by 115 million for half a year, with a growth rate of $108.1 \%$. According to the China Industrial and Commercial Research Institute, the share of bicycle users will reach 298 million in 2018, as shown in "Fig. 1".

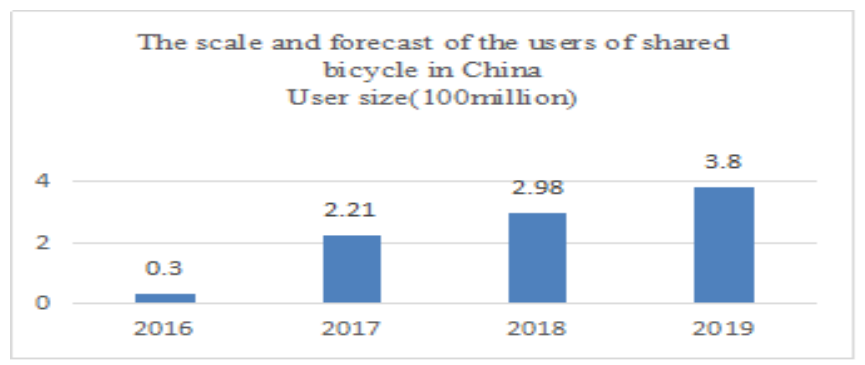

Fig. 1. The scale and forecast of the users of shared bicycles in China.

\section{The Market Size of Shared Bicycles}

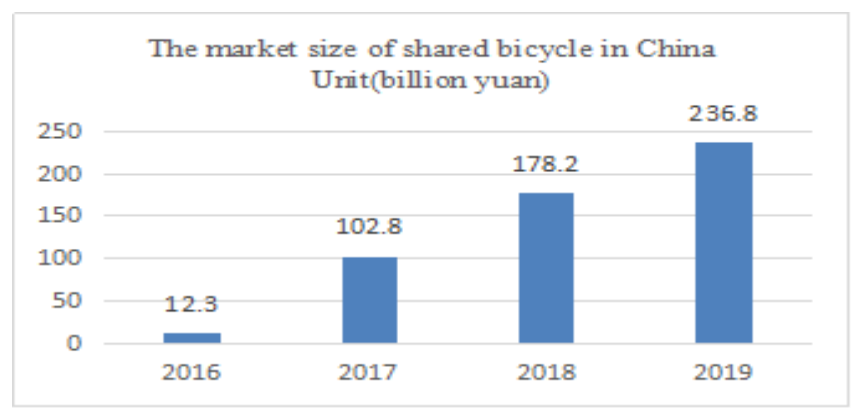

Fig. 2. The market size of shared bicycles in China.

As shown in "Fig. 2", the market scale of shared bicycle in 2016 is only 1 billion 230 million yuan, and in 2017, it increased to 10 billion 280 million yuan and increased by $736 \%$, as shown in "Fig. 2". According to the Research Report on the market prospects and investment and financing strategy shared by the China Commercial Research Institute for 2018-2023 years, the scale of the domestic bicycle market in 2018 will reach to 17 billion 820 million yuan, and the growth rate is $73.3 \%$. By 2020 , the domestic share market will exceed 30 billion yuan.

\section{PRoblems IN THE DEVELOPMENT OF SHARED BICYCLE}

Shared bicycle to some extent has changed the mode of urban residents' travel in the first-tier cities and alleviated the traffic pressure. However, some problems that need to be solved in the development process of shared bicycle have also been produced.

\section{A. Backwardness of Supporting Facilities}

The backwardness of the supporting facilities is in sharp contrast to the rapid shared bicycle. In December 2017, the number of users shared bicycle reached to 221 million, and the number of bicycles was more than 23 million. The number of bicycles has made the urban parking spaces more strained. There are few parking spaces and no special bicycle passages. The construction of these infrastructures is difficult to match with the development speed of shared bicycle.

\section{B. Lack of Government Support}

In order to make the shared bicycle industry develop healthfully, the government must increase support and pay attention to the problems exposed in the development process. The number of domestic shared bicycle enterprises, the fierce competition, the survival of the small and medium shared bicycle enterprises is very harsh, so the support of the government is very necessary for the development of small and medium shared bicycle enterprises. However, at present, the shared bicycle industry in China lacks the support of the government, which restricts the development of shared bicycle businesses to a certain extent.

\section{There Is a Risk in the "Pool of Funds"}

With the continuous expansion of the scale of shared bicycle users and the continuous emergence of shared bicycle companies, the "pool of funds" formed by the deposit is also expanding. The risk of "capital pool" mainly comes from two aspects: first, the deposit is concentrated in the hands of the enterprise, and it is not only lack of the supervision of the professional financial sector, but also the suspicion of "disguised collection or possession of funds". Second, if the deposit is collected and mismatched by the enterprise, the enterprise will lose the ability to return the deposit once the investment fails or the funds cannot be withdrawn in time.

\section{The Problem of the Refractory Deposit Is Highlighted}

With the intensification of competition, more and more shared bicycle businesses have been faced with operational difficulties, and some have even gone bankrupt and liquidated. For the users of shared bicycle, the problem of deposit is difficult to retreat, which greatly hinders the development of shared bicycles.

For example, Xiaoming bicycle has entered the stage of bankruptcy and liquidation. It also announces another failure of a shared bicycle company with a large number of users. According to the relevant data, the accumulative number of 430 thousand shared bicycle has been put in China, with a cumulative number of about 4000000 people, with a total of 
about 800 million yuan for the user's deposit, with a total of 199 yuan per person's deposit. Xiaoming motorcycle returns $80 \%$ user deposit, but 700 thousand users' deposit was not refunded.

\section{E. Excessive Release, Resulting in Urban Congestion}

The shared bicycle enterprises have been growing rapidly since 2016. According to the latest statistics of the Ministry of transportation, the number of shared bicycle enterprises in China is up to more than 70 . The competition of so many enterprises means that more shared bicycles will be shared and the shared bicycle market is saturated and even spillover, which not only causes shared bicycle market. It is a waste of resources, and it makes the already tense shared bicycle parking space become more serious, and the phenomenon of traffic jams caused by shared bicycle occupying motorized lanes. This situation is particularly prominent in the first cities in China. The number of shared bicycle with serious exceeding the standard occupies tense urban land, which has become a new traffic problem that the government has to face.

\section{Fiscal Suggestions to Promote Healthy DEVELOPMENT OF SHARED BICYCLES IN CHINA}

The shared service is provided by enterprises. The nature of its products belongs to quasi-public goods. The government should support its healthy development, strengthen guidance and supervision, and take certain fiscal measures to promote the healthy development of the shared bicycle.

\section{A. The Government Should Strengthen Guidance and Standardize the Shared Bicycle Industry}

The government should improve the access rules for the shared bicycle enterprises, strictly standardize the enterprises that have already entered the shared bicycle industry, determine the quantity of the shared bicycles with the population of the region, eliminate the unqualified, uncapable enterprises, encourage the merger of enterprises in the industry, and control the shared bicycle. The number of enterprises can not only control the waste of resources caused by disorderly competition, but also avoid the monopoly of enterprises.

\section{B. The Third Party's Independent Deposit System Is Established to Ensure the Safety of Funds}

On the one hand, we can learn from the securities market, in order to prevent the securities companies from misappropriating customer margin, the third party independent deposit system, the charge account and deposit account are managed separately. According to the principle of "enterprise management balance, bank deposit", the deposit deposit paid by the user through the third party payment platform is deposited into a special bank account, the third party is kept in custody, and the consumer organization and the platform enterprise jointly supervise the bank accounts, and show the content of the fund supervision agreement and the flow of funds to the public and the consumers. In the third party storage management model, the bank instead of the shared bicycle enterprise provides a deposit of the return service to the user, not only to distinguish between the deposit of the user and the business property of the enterprise, but also to prevent the deposit that the enterprise will charge for his use to ensure the security of the deposit of the user.

On the other hand, sharing bicycle companies can try to cooperate with the third party credit reporting agencies. The user's credit level is linked to the amount of deposit, giving different amount of deposit to the users of different credit levels. This kind of credit substitutes instead of deposit can control the capital risk of enterprises to a certain extent.

\section{Raise Fiscal Subsidies}

The investment of shared bicycle is huge, and the payback period is long. Many enterprises are still in a state of loss. In order to encourage the development of bicycle sharing enterprises, the government should gradually increase subsidies to share bicycle industry, support small and medium sized bicycle enterprises and help them develop. For example, the Changsha municipal government pays 20 million yuan a year to subsidize ofo in the development of public rental bicycles in the area. These attempts have played an important role in helping other cities' governments to help share bicycle businesses.

\section{Accelerated Depreciation of Fixed Assets to Increase Recovery and Depreciation of Shared Bicycles}

From the government's point of view, in order to reduce the operating cost of shared bicycle businesses, tax policies can be used to accelerate depreciation through fixed assets. Most of the operating cost of shared bicycle companies comes from shared bicycles. A share bicycle enterprise can enjoy the accelerated depreciation policy of fixed assets when it meets the conditions of one-time tax deduction. The government can improve the recovery and depreciation of the damaged bicycles and the abandoned bicycles, reduce the waste of resources, reduce the operation cost of the enterprise and promote the development of the sharing of the single car enterprises.

\section{CONCLUSION}

The development of shared bicycle in China has produced some problems that need to be solved urgently. Shared bicycle meets the needs of the people, and the government should take measures to make shared bicycle industry develop healthfully. The government can take financial measures to promote the healthy development of the enterprises, for example, the establishment of the third party independent deposit system, to ensure the security of funds, increase the financial expenditure, improve the construction of infrastructure, and raise financial subsidies. 


\section{REFERENCES}

[1] Xu Guangjian, Zhang Chun, Promoting the development of shared bicycle standardization strategies: based on the perspective of public management, China's Prices, February 2018.

[2] Guo Meng, Sharing bicycle market saturation research, Market Research, August 2017.

[3] Zhang Rongjin, OFO shared bicycle development strategy research based on SWOT model, Chinese Civil and Commercial, December 2017.

[4] Yang $\mathrm{Xu}$, Ponder over the sustained and healthy development of shared economy - take the management of shared bicycle deposit as an example, Shanxi Agricultural Economic Commission, April 2018.

[5] Zhao Xiaowei Fan Xiyu, Look at the development strategy of shared bicycles from Wukong bicycle delisting: based on the perspective of shared economy, The National Circulation Economy, September 2017.

[6] Han Xinyu, The analysis of civil liability in shared bicycles: liability for sharing bicycle and liability for breach of a pedestrian,Legal Expo, April 2018. 